\title{
ESPECIAL
}

\section{Nada mais prático que uma boa teoria}

\section{Prof. Floriano Freitas Filho*}

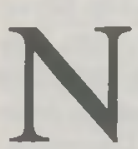
os dias de hoje parece estar se tornando modismo a concepção de que "na prática a teoria é outra" ou, o que é pior, algo como "teoria, ora teoria!", parodiando a famosa exclamação atribuida a Geıúlio Vargas, "lei, ora lei".

Em recentes seminários, um conferencista americano e outro japonês alertavam atônitos ouvintes para a distância entre teoria e prática profissional. Dizia o americano que os estudantes após formados haveriam de concluir da inutilidade de noventa por cento do que estudaram nas universidades, quer por discrepâncias entre teoria e prática, que por obsolescência dos ensinamentos. $\mathrm{O}$ japonês foi mais enfático: há um distanciamento cada vez maior entre escola e empresa; entre a escola de 2. grau e a moderna empresa esse distanciamento é total, pela inutilidade dos ensinamentos daquela - a própria empresa passa a ser a escola de habilitação profissional. Essa distância, segundo o conferencista, diminui relativamente a Universidade, mas mesmo assim uma e outra não se completam.

Um grande empresário perguntado sobre que tipo de formação superior seria a ideal para um alto cargo executivo, respondeu: - um músico ou um seminarista. Diante do espanto geral, acrescentou: esses estão devidamente preparados para apreender tudo o que a empresa precisa.

A distância entre Universidade e Empresa é um fato. Decorre, inicialmente, da natureza diversa de seus fins: uma produz, aperfeiçoa, inova e transmite conhecimentos, habilidades ou técnicas; outra os aplica. Há circunstâncias em que a produção se antecipa à aplicação; são raras e, pelo menos no Brasil, excepcionais. A regra é indicativa de tendência contrária: as necessidades de aplicação pressionam a produção e se as Universidades não respondem à pressão, as empresas integram às suas atividades as de pesquisa e desenvolvimento de tecnologia.

Por outro lado, o conhecimento gerado nas Universidades é geral - principal-

- Professor da Fundação Universidade de Brasília Departamento de Administração e colaborador na Escola Nacional de Administração. mente o das ciências sociais - em decorrência do rigor científico que se lhe exige, na busca constante da verdade, ainda que relativa. Já as empresas exigem o conhecimento particular, indispensável ao trabalho operacional, à ação. Ora, a prática por si só, sem uma orientação teóri$\mathrm{ca}$, induz o empirismo rudimentar ou a falta de racionalidade: o que se poderia chamar de um pequeno conhecimento (em relação ao todo), muito perigoso, pela visão supersimplificada do real, além de disfuncional como instrumento de análise.

Pode-se concluir, como muitos o vêm fazendo, inclusive professores, que as Universidades não estão cumprindo seus papéis? Que estão produzindo aquém do desejável e ensinando o obsoleto e o inútil?

Essas questões são bastante atuais ao ensino, nas Faculdades de Administração, em confronto com as atuais necessidades das organizações. Tornam-se relevantes, no Brasil, no momento em que o Governo se preocupa com institucionalizar organização que de há muito se faz essencial: a ENAP - Escola Nacional de Administração Pública, cujo curso de "Políticas Públicas e Gestão Governamental" está em fase de estruturação e implantação, com a finalidade de seleção, formação e aperfeiçoamento dos quadros superiores do pessoal civil da Administração Pública (art. 30 do Decreto n: 94.293 , de 29.04.87).

Ora, formar e aperfeiçoar gestores governamentais é, em suma, capacitar, no mais alto nivel, administradores.

Não se quer a ENAP como uma faculdade de Administração Pública; se assim fora, seria decisão de todo criticável, uma vez que o País já está devidamente estruturado com instituições para tal fim. Nem se pode desejar que seu Curso de Políticas Públicas e Gestão Governamental venha a ser um curso de pós-graduação em Administração Pública, pelas mesmas razões acima, já que qualquer Universidade, e sobretudo a UnB, estaria capacitada para tal, com menor custo e melhor resultado.

A criação da ENAP é um dos mais expressivos exemplos da necessidade que se quanto à presente produção científica e sente de preencher, institucionalmente, a distância entre exigências de conhecimentos, habilidades e técnicas essenciais ao dia-a-dia das organizaçōes e aqueles gerados nas Universidades. Algo assim como: uma coisa é administrar, outra é aprender sobre administração.

É fundamental, no responder àquelas indagações, compreender-se que a finalidade maior da Universidade é a educação geral, subsidiariamente cogitando da formação profissional. Como afirma Karl Jaspers, cabe à Universidade "procurar a verdade através da comunidade de pesquisadores e estudantes", ressaltando ser "direito da humanidade que a busca da verdade se realize em qualquer lugar sem constrangimento" (2). À formação profissional, portanto, é fase terminal do processo maior de educação, a qual apenas se inicia nas Universidades, nela prosseguindo em alguns cursos de especialização com esse objetivo, sem se esgotar.

No ensino da Administração, em particular, há que se ter presente que a arte de administrar se assenta num conjunto de conhecimentos, habilidades e técnicas gerados na experiência prática e n'outro conjunto de conhecimentos gerados através de pesquisas científicas, cujo objeto é a realidade universal das organizaçōes e da administração, dando origem às teorias da organização e da administração.

Chiavenato deixa isso bem claro ao afirmar: - "À medida que o ambiente de trabalho se torna cada vez mais turbulento e instável, maior a necessidade de opçōes diferentes para a resolução de problemas. À medida que o executivo em Administração se desloca de trabalhos operacionais voltados para o campo da ação onde utiliza suas habilidades práticas de saber fazer certas coisas corretamente para atividades administrativas propriamente ditas voltadas para o campo do diagnóstico e da decisão onde utiliza suas habilidades conceituais de diagnosticar situaçōes e de definir e estabelecer estratégias de ação adequadas maior a necessidade de se fundamentar em conceitos, valores e teorias que lhe permitam o balizamento adequado de seu comportamento"(3). 


\section{"A arte de administrar se assenta num conjunto de conhecimentos, habilidades e técnicas que a prática e a pesquisa científica indicam".}

Nesse sentido, o ensino de Administração nas Universidades deve ser prioritariamente conceitual e axiológico, assentado em teorias, investigando os porquês e os para quês das ações/decisões e não apenas o como fazer, distinguindo o mero executor (de planos, organogramas, orçamentos, lançamentos, registros, etc.) do analista, capaz de pensar, avaliar e ponderar em termos abstratos, estratégicos, conceituais e teóricos, sabendo resolver situações problemáticas variadas e complexas, atuando como agente de mudança e inovação, se necessário ${ }^{(4)}$.

Por outro lado, não se deve confundir como aprender com o quê aprender. Muitos criticam os atuais métodos de ensino nas universidades, responsabilizando-os pelos distanciamento entre ensino/aprendizado e exercício profissional. Ensina quem conhece; conhece conteúdos. Quem não conhece, poderá ter à sua disposição o mais variado e sofisticado elenco de técnicas e formas de aprendizado e não ensinará absolutamente nada. Aumentará apenas o fosso já existente.

Outros procuram rotular de acadêmicos os conhecimentos oriundos das universidades, contrapondo-os à validade de conhecimentos, habilidades e técnicas obtidas na vivência de situações reais e específicas, como se do conhecimento da parte, por amostragem, fosse possivel induzir o conhecimento do todo, generalizando ações/decisões administrativas.

Finalmente, há os que não acreditam na capacidade de resposta das atuais teorias da organização e da administração, por poucas, incipientes e ineficazes em seus propósitos de instrumentos de análise e previsão de fenômenos. Daí a melhor capacitação ainda ser a empírica, do particular para o geral, caso a caso.

$\mathrm{O}$ aprendizado de Administração não pode prescindir, em momento algum, da experiência prática, por mais singular e limitada que esta seja. Mas, dada a universalidade das organizações e a extrema complexidade do ambiente que as cerca, em contínua mutação, qualquer estudo que as tenha por objeto haverá de embasar-se em conhecimentos teóricos, por mais quantitativamente insuficientes que sejam. A falta desse embasamento conduziria qualquer esforço de aprendizado à visão singular, incoerente, inconsistente e disfuncional, em relação ao todo.

As teorias da organização e administrativas constituem um conjunto de proposiçōes derivado de um campo de estudo definivel: as ciências administrativas, ciências aplicadas, das quais resultam conhecimentos relevantes para a resolução de problemas ou para a tomada de decisões, nas organizações. Essas ciências possuem um corpo de conhecimentos básicos e seus próprios métodos e que se aplicam sobre um grupo especial de problemas, com resultados observáveis. Dada a universalidade das organizações, essas teorias são ecléticas e os estudos cientificos que lhas embasam são extremamente amplos e diversificados. São teorias que devem ser vistas como sistemas compostos de subsistemas de disciplinas relevantes: história, psicologia, antropologia, economia, ciências políticas, ciências jurídicas, ciências contábeis, filosofia, matemática, etc. $\mathrm{O}$ que extrair de relevante dessas disciplinas é um dos objetivos que caracteriza o estudo teórico das organizaçōes e sua administração, com um embasamento cientifico. ${ }^{(5)}$

Cabe à Universidade o aprimoramento contínuo dessas teorias, para tanto exigindo-se mecanismos de pesquisa ainda não existentes na maioria das Faculdades ou Departamentos de Administração e que viabilizem a desejável integração de conhecimentos entre Universidadeorganizações, na coleta de experiências e necessidades práticas, além da permanente e profícua interação entre os vários Departamentos responsáveis pelas áreas de conhecimento que compōem essas teorias. Estruturar e aprimorar esses canais de comunicação é indispensável para se precisar e ampliar conteúdos teórico-administrativos, antes de se preocupar com formas alternativas de ensino/aprendizado.
No que se refere à ENAP, em particular, os cursandos dessa escola de aplicação irão ter por objeto a "organização" Estado e por objetivo como administrálo, suas partes ou seu todo, sob a égide das políticas públicas. Em decorrência, não podem deixar de embasar seu aprendizado num corpo teórico de conhecimentos cujo objeto especifico seja a organização (Estado) e sua administração (gestão governamental), o qual - por menor que seja - irá delimitar as áreas de conhecimento das demais ciências que o compõem. Se assim não for, perder-se-ão os enapianos numa infinidade de conteúdos ou de formas de aprendizado que constituirão algo inconsistente, incoerente e que os conduzirá à frustração.

Por outro lado, a ENAP, em atuando juntamente com as Universidades, poderá vir a se constituir num excepcional laboratório, fornecendo os elementos essenciais à pesquisa e à estruturação e evolução das teorias da organização e da administração do Estado.

Afinal, não devemos esquecer que toda teoria tem sua gênese numa hipótese extraída da realidade, na qual é testada e validada no seu poder de descrever e prever fenômenos que compōem essa realidade.

O Estado, visto como "organização" (nação politicamente organizada) administrável (dirigida por governo próprio) é realidade muito pouco teorizada, no Brasil, e, por isso mesmo, há de ser o permanente objeto de observação científica da ENAP - o que só será possivel através de sua contínua e efetiva interação com as Universidades.

\section{NOTAS BIBLIOGRÁFICAS}

1. Afirmação atribuida a KURT LEWIN, uma das expressivas figuras da Teoria das Relações Humanas.

2. KARL JASPERS. apud ANTUNHA, Heládio Cesar Gonçalves - Universidade de São Paulo. Fundação e Reforma; São Paulo, MEC/INEP, 1974, pp. 34.

3. e 4. CHIAVENATO, Idalberto, Teoria Geral da Administração, 3a ed., São Paulo, McGraw-Hill, 1987, Vol. I - Introdução.

5. ver KAST, fremont E. \& ROSENZWEIG, James E., Organização e Administração: um enfoque sistêmico, 2. ed., SP. Pioneira, 1980, Capitulo I. 